AperTO - Archivio Istituzionale Open Access dell'Università di Torino

Species are, at the same time, kinds and individuals: a causal argument based on an empirical approach to species identity

This is a pre print version of the following article:

Original Citation:

Availability:

This version is available http://hdl.handle.net/2318/1706310

since 2021-01-19T11:33:10Z

Published version:

DOI:10.1007/s11229-019-02199-5

Terms of use:

Open Access

Anyone can freely access the full text of works made available as "Open Access". Works made available under a Creative Commons license can be used according to the terms and conditions of said license. Use of all other works requires consent of the right holder (author or publisher) if not exempted from copyright protection by the applicable law. 
Dear Author,

Here are the proofs of your article.

- You can submit your corrections online, via e-mail or by fax.

- For online submission please insert your corrections in the online correction form. Always indicate the line number to which the correction refers.

- You can also insert your corrections in the proof PDF and email the annotated PDF.

- For fax submission, please ensure that your corrections are clearly legible. Use a fine black pen and write the correction in the margin, not too close to the edge of the page.

- Remember to note the journal title, article number, and your name when sending your response via e-mail or fax.

- Check the metadata sheet to make sure that the header information, especially author names and the corresponding affiliations are correctly shown.

- Check the questions that may have arisen during copy editing and insert your answers/ corrections.

- Check that the text is complete and that all figures, tables and their legends are included. Also check the accuracy of special characters, equations, and electronic supplementary material if applicable. If necessary refer to the Edited manuscript.

- The publication of inaccurate data such as dosages and units can have serious consequences. Please take particular care that all such details are correct.

- Please do not make changes that involve only matters of style. We have generally introduced forms that follow the journal's style.

Substantial changes in content, e.g., new results, corrected values, title and authorship are not allowed without the approval of the responsible editor. In such a case, please contact the Editorial Office and return his/her consent together with the proof.

- If we do not receive your corrections within $\mathbf{4 8}$ hours, we will send you a reminder.

- Your article will be published Online First approximately one week after receipt of your corrected proofs. This is the official first publication citable with the DOI. Further changes are, therefore, not possible.

- The printed version will follow in a forthcoming issue.

\section{Please note}

After online publication, subscribers (personal/institutional) to this journal will have access to the complete article via the DOI using the URL: http://dx.doi.org/[DOI].

If you would like to know when your article has been published online, take advantage of our free alert service. For registration and further information go to: http://www.link.springer.com.

Due to the electronic nature of the procedure, the manuscript and the original figures will only be returned to you on special request. When you return your corrections, please inform us if you would like to have these documents returned. 


\section{Metadata of the article that will be visualized in OnlineFirst}

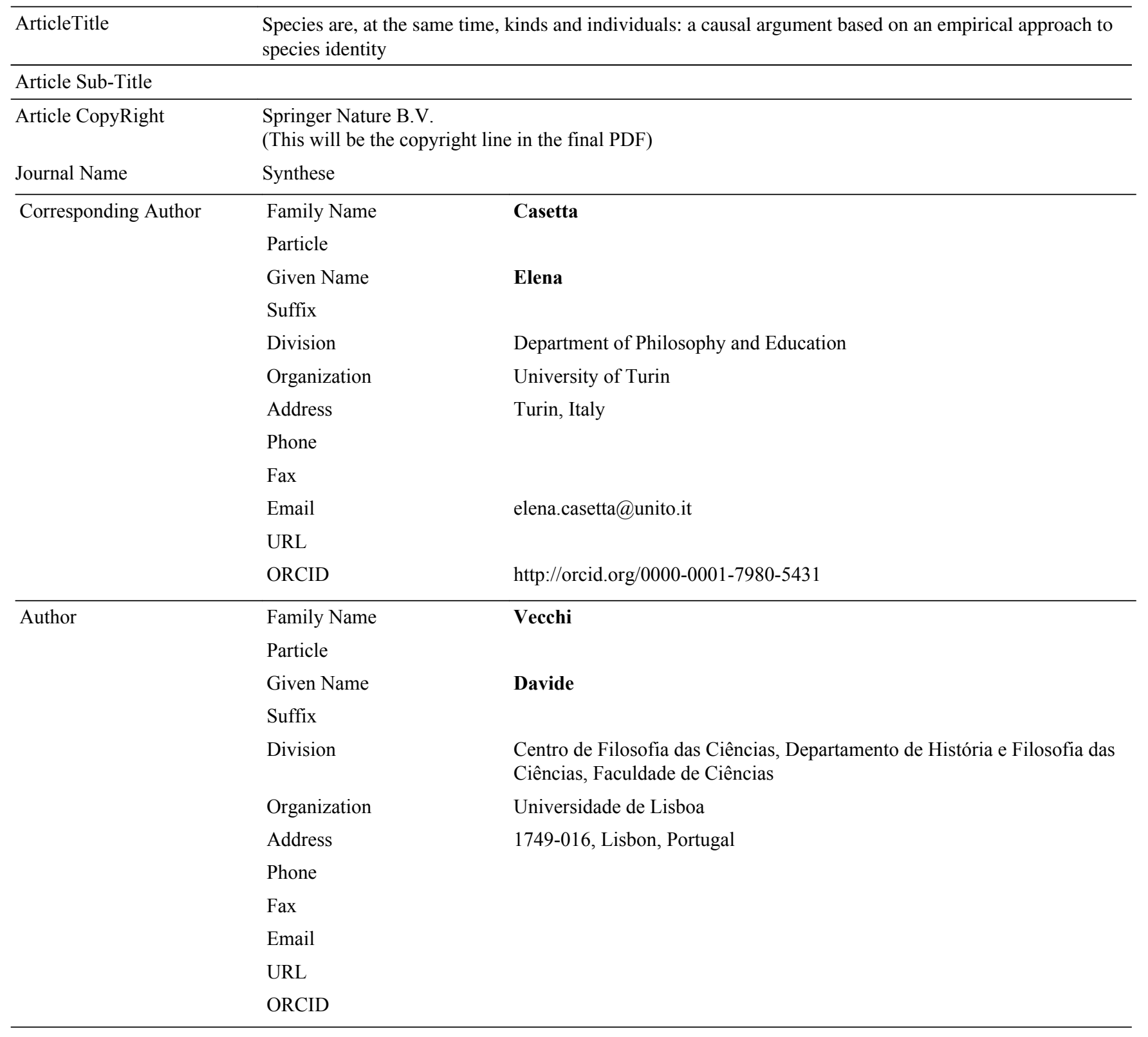

\begin{tabular}{ll}
\hline Schedule & $\begin{array}{l}\text { Received } \\
\text { Revised } \\
\text { Accepted }\end{array}$ \\
\hline Abstract & $\begin{array}{l}\text { After having reconstructed a minimal biological characterisation of species, we endorse an "empirical } \\
\text { approach" based on the idea that it is the peculiar evolutionary history of the species at issue-its peculiar } \\
\text { origination process, its peculiar metapopulation structure and the peculiar mixture and strength of } \\
\text { homeostatic processes vis à vis heterostatic ones—that determine species' identity at a time and through } \\
\text { time. We then explore the consequences of the acceptance of the empirical approach in settling the } \\
\text { individuals versus kinds dispute. In particular, while conceptual arguments have been proposed to show } \\
\text { that species can be equally treated as individuals and kinds because mereology's and set-theory's } \\
\text { languages are inter-translatable, we advance instead a causal argument to sustain the claim that each }\end{array}$
\end{tabular}


species is both a kind (i.e., a class whose members share some properties included in a cluster) and an individual (i.e., a whole made of parts).

Keywords (separated by '-') $\quad$ Biological species - HPC kinds - Species-individuals

Footnote Information 


\title{
Species are, at the same time, kinds and individuals: 3 a causal argument based on an empirical approach 4 to species identity
}

\section{Elena Casetta ${ }^{1}$ D $\cdot$ Davide Vecchi $^{2}$}

Received: 30 April 2018 / Accepted: 1 April 2019

c) Springer Nature B.V. 2019

\begin{abstract}
After having reconstructed a minimal biological characterisation of species, we endorse an "empirical approach" based on the idea that it is the peculiar evolutionary history of the species at issue-its peculiar origination process, its peculiar metapopulation structure and the peculiar mixture and strength of homeostatic processes vis à vis heterostatic ones-that determine species' identity at a time and through time. We then explore the consequences of the acceptance of the empirical approach in settling the individuals versus kinds dispute. In particular, while conceptual arguments have been proposed to show that species can be equally treated as individuals and kinds because mereology's and set-theory's languages are inter-translatable, we advance instead a causal argument to sustain the claim that each species is both a kind (i.e., a class whose members share some properties included in a cluster) and an individual (i.e., a whole made of parts).
\end{abstract}

Keywords Biological species $\cdot$ HPC kinds $\cdot$ Species-individuals

\section{Sexual species from a biological point of view}

A longstanding disagreement about what species are persists. A glance at the literature on the so-called "species problem" reveals that more than twenty concepts of species have been, and still are, employed (Stamos 2003; Wilkins 2009; Richards 2010; Ereshefsky 2010). A way to overcome this disagreement is to make reference to the distinction between a very general species concept (capturing what all species concepts have in common) and different operational criteria (de Queiroz 2005a, b,

Elena Casetta

elena.casetta@unito.it

1 Department of Philosophy and Education, University of Turin, Turin, Italy

2 Centro de Filosofia das Ciências, Departamento de História e Filosofia das Ciências, Faculdade de Ciências, Universidade de Lisboa, 1749-016 Lisbon, Portugal 
2007) or standards of application (LaPorte 2007). ${ }^{1}$ For instance, de Queiroz argues AQ1 that a general concept of species can be singled out because "...virtually all contemporary definitions of the species category are based on a common general concept of species: the concept of species as (segments of) metapopulation lineages" (de Queiroz 2005a: p. 6602). According to this view, to be segments of separately evolving metapopulation lineages is the only essential property for being a species. All the other properties identified by species concepts are contingent in the sense that they not only are typically acquired at different times during the speciation process (e.g., two lineages can become phenotypically distinguishable before developing reproductive barriers), but also in the sense that they might or might not be acquired during the course of the history of the metapopulation lineage. Making mainly reference to de Queiroz' version of the general species concept, the question to which our contribution tries to give an answer is twofold: first, what follows from endorsing a general species concept concerning the identity of species taxa (i.e., their criteria of diachronic and synchronic identity)? And, secondly, what is their metaphysical status (i.e., which kind of entities they are)?

In order to answer the above questions, we firstly need to examine the concept of metapopulation and the related concept of Mendelian population more closely.

Metapopulation structure and dynamics, depending on the actual historical and geographical relations among the species subpopulations, play a fundamental role in determining species' identity. According to Levins (1970), who firstly introduced the term, a metapopulation consists of several spatially discrete local populations connected through migration and recolonization. The cohesiveness of the metapopulation as well as its vulnerability to extinction depends on its structure and dynamics (i.e., the size and interactions between the constituent populations) which varies from species to species.

The components of metapopulations are Mendelian populations. The concept of Mendelian population was originally elaborated by Wright (1931) and Dobzhansky. The latter defined a Mendelian population as a reproductive community of sexual and cross-fertilizing individuals sharing a common gene pool (Dobzhansky 1950: p. 405). Two features of Mendelian populations should be highlighted. Firstly, the attainment of reproductive isolation between genetically diverging populations is "the essence of biological speciation" (Dobzhansky 1950: p. 415). Secondly, the origin and maintenance of isolating mechanisms are two different processes, the first leading to divergence of lineages, the second to the maintenance of the species' gene pool (Mayr 1988: p. 433).

It might be tempting to identify species with gene pools (Ridley 2004: p. 345). But this identification is problematic. Stamos (2003: p. 195), for instance, argues that if a species "literally is a protected gene pool", then it also cannot "literally $b e$ " a group of interbreeding natural populations, on pain of contradiction. Additionally,

1FL01 ${ }^{1}$ Even though the general species concept is quite agreed upon when species of sexually reproducing 1 FL02 organisms are at stake, its applicability to asexual species has been questioned (see for instance Doolit1FL03 tle and Zhaxybayeva 2009; and see Samadi and Barberousse 2006 for a possible way to overcome this 1 FL04 problem). 
identifying species with gene pools would imply a very strong reductionist position at odds with the metapopulational approach, which makes reference to interactions among populations, such as migration and colonization, without reducing them at the genetic level. Accordingly, we prefer to speak of characterization rather than identification. Moreover, we would not like to dismiss, in principle, the possibility that both phenotypic properties and non-genetically inherited properties might be relevant for species characterisation. Concerning phenotypic properties, consider the following example. Seasonal polyphenism (either/or phenotypes elicited by environmental induction, e.g., temperature) in many butterfly species can lead to fixation of alternative phenotypes in geographically isolated populations. The pattern of evolution is first the production of alternative phenotypes with same genetic basis by developmental plasticity and then reproductive isolation, causing speciation (West-Eberhard 2003, p. 532). In this case, characteristic phenotypes of species are relevant for speciation. Concerning non-genetically inherited properties, it has been argued that, for instance, epigenetic inheritance may be important for adaptation, especially when the available genetic variation is scarce, because it might enable survival in dynamic environments (e.g., climate change effects) before genetic adaptation evolves (Burggren 2016). If so, then non-genetically inherited properties may guarantee the persistence over time of a species.

For these reasons, we propose to replace the gene pool concept with the more comprehensive concept of gene-phene pool. Mayr (1970: p. 417) defined the gene pool as "The totality of the genes of a given population existing at a given time." Analogously, we define the concept of gene-phene pool as the totality of the genetic and phenotypic properties of a given population or metapopulation existing at a given time. ${ }^{2}$ The concept of gene-phene pool provides a genetic and phenotypic characterization of sexual species that complements the ecological characterization provided by the metapopulation concept. Importantly, notice that the metapopulation structure and dynamics (i.e., the size and migration and colonization patterns of the populations that make up the metapopulation) co-determine the nature and the formation of the gene-phene pool of the species (e.g., a migration from one population to another population of the same metapopulation can be a means through which gene flow occurs in the metapopulation).

To sum up, despite the multiplicity of species concepts, a minimal characterisation on what sexually reproducing species are can be pointed out:

(MC) Species of sexually reproducing organisms are segments of metapopulation lineages whose constituents are Mendelian populations characterized by their own gene-phene pool.

\footnotetext{
${ }^{2}$ It is important to emphasise that the concepts of gene pool and gene-phene pool could be defined by taking into consideration the extant organisms of the species-like Mayr does-or by taking into account all its past, present and future members. This latter characterization clearly shows the indefiniteness of the concepts of gene pool and gene-phene pool. Furthermore, it is also important to note that, unlike Mayr, we prefer to use the term "genetic property" in order to define the concept of gene-phene pool; the reason is that this latter term is more general and neutral as it might also refer to sequences of DNA with not yet known functional role in development.
} 
Three clarifications are in order. First, whether the populations of a metapopulation are Mendelian populations or not is an open empirical issue (E.O. Wilson 1975: p. 51). Here, for simplicity, we assume that all the populations in a segment of a metapopulation lineage are Mendelian populations. Second, it is tempting to merge the two concepts of metapopulation and Mendelian population-which are in fact very close-and claim that a species is the largest Mendelian population, as Dobzhansky did (1950: p. 406). We prefer to maintain the concepts separated. There are cases in which as a matter of fact a species is a Mendelian population without being a metapopulation: think of the only extant population of a critically endangered species localised in a small territory; it is highly likely that, in the past, this species exhibited a metapopulation structure (i.e., being constituted of geographically distributed Mendelian populations) and that its present status is the result of its past metapopulation dynamics. So, in order to be able to account for past metapopulation dynamics that have played a fundamental role in determining the identity of a species, it is methodologically useful to keep the concepts separated. Third, it should be noted that the minimal characterization sketched provides a two-level definition making reference, on the one hand, to the genetic and phenotypic level (through the concept of gene-phene pool) and, on the other hand, to the ecological level (through the concept of metapopulation). Whether the two levels could be reduced to each other is an issue we are not going to consider in this article.

\section{The identity of species}

Given the minimal characterisation of species articulated in the previous section, we can proceed to answer the first part of our twofold metaphysical question concerning species' identity. We suggest that the identity of a species is determined by the limits of the relevant metapopulation lineage segment and the relative cohesiveness of its gene-phene pool. As it will become clear, we do not endorse the view that it will inevitably be possible to clearly determine the limits of the segment and the level of cohesiveness required to be a species. Nonetheless, in principle the determination of the limits of the segment is possible by making reference to the nature of the relevant speciation process, while the determination of relative cohesiveness of the gene-phene pool is possible by making reference to the metapopulation dynamics and the biological processes producing and maintaining lineage cohesiveness or, conversely, generating divergence among lineages. It is for this reason that the concepts of Mendelian population characterized in terms of gene-phene pool and metapopulation are useful epistemological tools to answer the identity question.

The MC suggests that only by knowing the speciation process, the peculiar metapopulation dynamics and the distinctive gene-phene pool it becomes possible to recognize a particular segment of a lineage as a species and, furthermore, as that particular species. This is the core message of the empirical approach we endorse. Since the speciation process, the metapopulation dynamics and the distinctive gene-phene pool differ in each species case, every single species taxon should be considered as an entity on its own. In order to show this, consider a species with its own metapopulation structure. Each species underwent its peculiar speciation process, has its own 
peculiar history and is characterised by its unique metapopulation structure (i.e., a given sequences of generations of Mendelian populations over time) and dynamics (migrations and colonisations). Moreover, the ties that keep together, on the one hand, the members of Mendelian populations and, on the other hand, the Mendelian populations of the metapopulation, can be of different type in different species. For instance, the members of one species might be kept phenotypically homogeneous by stabilising selection while the members of another might be kept phenotypically homogeneous by the curtailment of mutation through processes enhancing genomic stability (e.g., DNA editing) or by developmental homeostasis (i.e., a process that canalises the development of the organisms of the species). Additionally, the developmental and evolutionary processes keeping together the members of Mendelian populations as well as the Mendelian populations of the metapopulation may also display different strengths at different times of a species life. For instance, gene conservation through stabilising selection might be stronger in different phases of the life of the species (see Sect. 3.3).

In our view, each sexual species is thus identified, first, by its peculiar speciation process; second, by the specific combination of the types of processes maintaining its cohesion (see Sect. 3.2); and third, by the specific strength of such maintenance processes (see Sect. 3.3). Accordingly, we propose that a species' identity is determined by its integrating principle (Colless 2006), which is constituted by two sorts of processes:

(i) Origination processes, i.e., the kind of processes through which the species originated or, put in other words, that allow us to identify the limits of the metapopulation lineage segment at issue;

(ii) Homeostasis processes, i.e., the processes maintaining lineage cohesiveness or, in other words, in virtue of which a species persists over time, in spite of the changes it undergoes, as one and the same species.

Given the contingency of the historical process a species undergoes (represented by, e.g., its geographical separation, its history of mutation, its metapopulation dynamics), it seems clear that every species has a peculiar history that leads in peculiar ways (i.e., through the causal action of a peculiar mixture of evolutionary processes) to the formation and maintenance of its distinctive gene-phene pool.

\section{Sexual species from a metaphysical point of view}

The perspective sketched so far takes as departure point the general concept of species put forward by de Queiroz, i.e., a definition of the species category, and thenadopting the empirical stance suggested by the MC - moves to consider species taxa and their identity conditions. We would now like to argue that this empirical approach may help in settling the vexata quaestio whether species taxa should be conceived as individuals (SAI) or as kinds, more specifically as a peculiar sort of natural kinds defined on the basis of homeostatic property clusters (HPC), answering the second part of the twofold metaphysical question articulated in Sect. 1. De 
Queiroz (1999: p. 67 ff.) pointed out that the general species concept is compatible with conceptualizing species as either individuals or classes. We shall defend a stronger metaphysical claim, namely, that species are individuals and kinds at the same time. ${ }^{3}$ More specifically, we shall argue that the fact that species are individuals and kinds at the same time causally follows from the minimal characterization given above. Our argument proceeds as follows. In Sect. 3.1 we illustrate the main conceptual arguments that have been proposed to show that species can be equally treated as individuals and as kinds. These arguments are typically based on the inter-translatability of the two respective languages (i.e., mereology's and settheory's languages). In Sect. 3.2, we take things a step further by arguing that the issue concerning the metaphysical status of biological species is not to be solved by uncovering whether the relationships between individual organisms and the species they belong to are set-theoretical or rather mereological, but by understanding their biological nature. Finally, in Sect. 3.3 we shall highlight that, as we have anticipated in Sect. 2, species' identity through time also depends on the strength of homeostatic processes. In fact, homeostatic processes maintaining species integrity (i.e., the integrity of its gene-phene pool) clash with the processes creating (heterogenic) and maintaining (heterostatic) genetic and phenotypic variation (Ereshefsky and Matthen 2005). In case the latter prevail, the integrity of the species might be compromised, possibly leading to speciation.

\subsection{SAI versus HPC}

According to SAIsts (Ghiselin 1974; Hull 1978; Eldredge and Gould 1972; Brogaard $2004)^{4}$ species taxa are to be treated as spatio-temporally localized individuals, made up of parts (i.e., organisms) related by descent. The relation between organisms, populations and species taxa would then be construed as a part-whole relation (i.e., a mereological relation) instead of a class-membership relation (i.e., a settheoretical relation), thus avoiding - at least according to Ghiselin (1974)—intrinsic essentialism. It should be noted that there are two prima facie incompatible ways to characterise the SAI thesis. SAI might be seen as (a) a mereological thesis according to which species are spatio-temporally localized individuals (concrete particulars) made up of causally related parts (i.e., organisms). An advocate of this version of SAI is Ghiselin (1974: p. 536), who claims of taking the term "individual" in its logical sense-i.e., "not a synonym for "organism" - but rather as merely designating concrete particulars as opposed to abstract entities such as sets or classes. Otherwise, SAI might be characterised as (b) the thesis that species are "organismal" in the sense of displaying organism-like properties such as a certain level of functional integration. Hull $(1976,1978)$ sometimes seems to endorse this version of SAI: "they [species] possess all the characteristics of individuals-that is, if organisms are taken to be paradigm individuals" (Hull 1976, p. 174). In this article, we shall

\footnotetext{
3FL01 3 de Queiroz (1995) admits the same possibility, on the basis of mainly semantic considerations.

4FL01 ${ }^{4}$ The historical roots of the thesis are much older, going back at least to Buffon (Gayon 1996).
} 
consider the mereological thesis as our main target. Notice, however, that the two theses are different but not incompatible. One way to understand the relationships between these two characterisations is through genidentity (Hull 1992). Genidentity (see below in this section) is in this sense both a mereological relationship and an account of organismality. In the first sense, organisms are the states of the biological trajectory of the genealogical lineage, while in the second sense species are cohesive units of organisms analogous to the cohesive units of cells constituting multicellular organisms.

In our view, (b) might be seen as a particular case of (a): under certain conditions, the causal relations connecting the parts of a species might become tighter and being of the relevant type as to consider a certain species (or a temporal part of it) as an organism-like entity. If organismality is a matter of degree and has to do with the balance between cooperation and competition, when competition among the parts of a species is higher than cooperation, the species will be less organism-like, and vice versa (Queller and Strassman 2009).

The major rival of the individuality view is HPC (endorsed in different versions by authors like Boyd 1999; Wilson et al. 2007; Brigandt 2009). ${ }^{5}$ The core idea of the HPC view is that species are to be treated as natural kinds whose members share some of the properties included in a cluster, or a "family" (Boyd 1999: p. 143) of properties exhibiting some degree of correlation (i.e., typically co-instantiation). Each species member possesses several of these properties, though usually not all of them, and none of them must necessarily be shared by all the members of the kind (thus overcoming the problems of traditional essentialism). ${ }^{6}$ Moreover, unlike traditional kinds, HPC kinds can account for the fact that a species is a historical entity by recognizing historical relations (e.g., the relation of descent) as one type of homeostatic mechanism at the basis of the clustering. ${ }^{7}$ The family of properties is indeed "contingently clustered in nature" (Boyd 1999: p. 143) in the sense that these phenotypic or genetic features co-occur in an important number of cases in virtue of underlying causal processes (i.e., homeostatic processes) that tend to maintain their co-occurring presence. ${ }^{8}$

A third metaphysical position concerning specieshood is worth mentioning for its closeness to that hereby defended, namely that species are historical entities.

\footnotetext{
5 An alternative account taking Boyd's HPC view as a departure point has been recently offered by Slater (2013, 2015), who suggests replacing the notion of homeostatic property clusters with the notion of stable property clusters (SPC).

6 Whether all the extant (or even past and future) organisms of a species actually share a set of intrinsic properties remains an open empirical issue that cannot be settled philosophically (Devitt 2008; Barker 2010).

7 We characterise a cluster in terms of intrinsic and relational properties. Wilson et al. 2007 argue that a cluster consists of both kinds of properties for the reason that “... the features that promote cohesion within a species [i.e., that keep the cluster homeostatic] are typically relational properties of conspecifics..." Our argument does not depend on privileging relational over intrinsic properties.

8 It is interesting to note that no definite list of homeostatic mechanisms has been provided. In our opinion, the reason for this omission is simply that homeostasis is species-dependent: the homeostatic mechanisms at play depend on the peculiar speciation process and metapopulation structure and dynamics and thus may vary over time and/or space.
} 
According to Ereshefsky (2014: p. 714), a species' identity "is not determined by its intrinsic properties or its origin, but by its unique evolutionary path". A similar view was already defended by Hull (1992), who argued that genidentity is the only available criterion of individuality for supra-organismal aggregates such as species. The genidentity criterion can be characterised as the thesis that an object can be individuated through time not by retention of intrinsic properties but because of its continuous historical relationship to its previous states in the context of its life history trajectory. Genidentity is thus a historical relation purely characterisable in terms of the causal relationship between the various life history states of the object. From this perspective, it follows that the organisms constituting a species do not belong to it because they share intrinsic properties. Thus, the historical identity of a species can only be grounded on its unique evolutionary origin and on the phylogenetic relationship that its constituent organisms have with such origin as spatio-temporal parts of that genealogical nexus (i.e., a genidentity relationship). Thus, Hull's and Ereshefsky's positions are similar in the sense that both consider species as path-dependent historical entities, while they significantly differ because species' origin is not taken as part of the identity criterion by Ereshefsky. Unlike Ereshefsky, we shall consider the biological nature of the origination process as a crucial ingredient for the identity of species.

HPC and SAI have usually been presented by their respective supporters as ontologically incompatible. For instance, in reviewing Duprés (1995) book, Wilson (1996: p. 310) pointed at the fact that it is "an absurdity" to say "that one and the same thing is a natural kind and an individual" since "individuals and kinds belong to fundamentally different ontological categories".

Wilson's view is not universally shared. In fact, the supposed ontological incompatibility between kinds and individuals has been treated by many authors with a certain dose of scepticism. Some have argued that the issue matters more to philosophers rather than to biologists (Assis and Brigandt 2009), and others have raised doubts concerning its significance. Hull himself, in the conclusion of his paper on SAI (Hull 1976), mentioned that "perhaps the distinction between individuals and classes is too crude", and Boyd (1999: p. $162 \mathrm{ff}$.) suspected that the incompatibility issue might have been somehow inflated in the literature. Moreover, Okasha (2002: p. 193) claimed "that it is largely a matter of convention whether species are conceptualized as individuals, kinds or historical entities", echoing Dupré (1995: p. 43) who wrote that: "in some contexts species are treated as individuals, in others as kinds". The argument usually brought in favour of the consistency between the two views may be called "the argument from inter-translatability": "An organism is 'a part of a species-individual' on SAI, while the HPC view has to conceptualize this organism as 'a member of a species-natural-kind', and translate any talk about organisms accordingly (and vice versa for SAI)." (Brigandt 2009: p. 85) This argument avoids taking a stance on what species are, both from a metaphysical and a biological point of view, effectively considering the issue merely conceptual or linguistic: a certain portion of the biological realm can be conceptualized and 
described in mereological terms as well as in set-theory terms. ${ }^{9}$ In fact, the main difference between the two ways of speaking is that mereology is not committed to the existence of abstract entities — such as classes or sets-, while set-theory is (this does not mean that mereology is committed to concreta instead: the whole can be as concrete as the parts, and the parts can be as abstract as the whole-see Varzi 2016). But this difference does not seem to play any substantial role in the case of biological species. In speaking of species taxa as kinds, what we are interested in is not abstract entities but, rather, their concrete members with their properties. For instance, by saying that "species evolve" we are not aiming to say that there is an abstract entity - a class - that evolves (abstract entities cannot evolve by definition). What we might mean is that, over time, the frequency of a certain phenotype (i.e., a property of individual organisms, namely the members of the species at issue) has increased or decreased in the population of reference. ${ }^{10}$ The very same point can be expressed in terms of parts (Okasha 2002; LaPorte 2004; Brigandt 2009).

The intertranslatability argument states that the two languages-mereology's and set-theory's-have an equivalent expressive power or, conversely, that the same portion of reality can be equally well described by means of the two different languages. On the contrary, we shall argue that SAI and HPC could be closer than it seems at a first glance also in virtue of biological considerations. In the next section, we argue that the empirical approach provides a biological foundation for the intertranslatability argument. Our argument is not an entirely new one. It is close, under some respects, to Rieppel's (2007, 2009) and LaPorte's (2004), according to whom species are both kinds and individuals: "where there are properties, there are natural kinds. ... As long as it is admitted that talk about species have causally grounded properties, it also has to be admitted that talk about species as individuals can be translated into talk about species as natural kinds (LaPorte 2004)" (Rieppel 2007: p. 378). But it has two important differences. First, we do not endorse Rieppel's conclusion that the fact that species are kinds means that they are "single members of their own specific natural kinds", i.e. "complex wholes (particulars, individuals) that instantiate a specific natural kind" (Rieppel 2007: p. 373), for we see no reason in considering each species as a member of its own kind, which would multiply entities unnecessarily. What we do claim is that each species is both a kind (i.e., a class whose members share some properties included in a cluster) and an individual. Of course, this implies a conflation of the distinction between kinds and individuals; we accept this implication, seeing it as a low price to pay.

\footnotetext{
"We use the terms "class" and "set" as synonymous and as intensionally defined.

${ }^{10}$ This is called, by Kitcher (1984), "The fallacy of incomplete translation". Kitcher reconstructs the argument in favour of SAI as follows: Sets cannot evolve; species evolve; hence species are not set. In the argument, "species evolve" is, according to Kitcher, left untranslated. To complete the translation, we need to consider that a species, set-theoretically conceived, is a union of subsets-or stages. A stage is the set of organisms belonging to the species which are alive at a given time. Accordingly, the complete translation of "species evolve" would be something like: the frequency of the distribution of (genetic or genetic plus phenotypic) properties at one stage will differ from the frequency of the distribution of (genetic or genetic plus phenotypic) properties at a later stage. Proceeding in this way, Kitcher argues, claims about the evolutionary behaviour of species—such as for instance speciation or extinction-may be easily expressed in set-theoretical terms.
} 
Consider that the master argument provided by SAIsts in favour of their view is the following: species evolve; abstract entities (such as kinds) are atemporal entities, thus they cannot evolve; then, species are not kinds. But, as Kitcher (1984) and LaPorte (2004) have shown, abstract entities can be made compatible with evolution once the fallacy of incomplete translation is recognized. The metaphysical distinction lying behind the argument is that between abstract and concrete entities, whereas abstract entities are identified with sets or classes, and concrete entities with individuals or particulars. However, such identification is questionable: just as there might be abstract individuals (such as, for instance, numbers), there might be concrete kinds, i.e., either a kind may be identified with its members or with its defining properties, where these properties are understood as concrete particulars (i.e., individualized properties).

Moreover, as Reydon (2009) has argued, Rieppel's reconciliation between kinds and individuals is merely an epistemological, not a metaphysical argument. Our position is a stronger one: species are at the same time kinds and individuals in a metaphysical (and biological) sense, and not only because conceiving them as such is required by different kinds of biological explanations, or allowed by the intertranslatability of sets-talk and part-whole talk. The fact that species taxa are both kinds and individuals is a consequence — so we argue — of the way in which some lineage segments originate, evolve, and become extinct.

\subsection{A causal argument for compatibility}

The empirical approach addresses the question concerning the metaphysical status of species taxa in these terms: each species is at the same time an individual and a kind individuated by its characteristic origination process, its characteristic gene-phene pool and its characteristic metapopulation structure and dynamics. The twofold metaphysical status of species taxa depends on this biological characterization, rather than on purely linguistic or conceptual considerations. The reason is that organisms participate in species-specific biological processes, and this participation, as well as those processes, is what makes them both parts of wholes and members of classes. This participation is causally primary since, without it, there would simply be no species at all, and hence it should inform the metaphysical analysis of species in so far as they are biological entities. Certain species-specific causal relations hold among the organisms that make a species (e.g., relations of descent or reproduction), as well as between those organisms and the species (e.g., relations of part-hood or membership). When those relations hold, an entity which is at the same time an individual and a kind is what we are dealing with. For instance, consider common descent. Organism $a$ is part of the whole/species $S$ when it is genealogically related to another organism $b$, where $b$ is a recognised part of $S$; and, at the very same time, that same organism $a$ is a member of class/species $S$ because it shares $n$ properties of the cluster $C$ characterising $S$ with $b$, where $b$ is a recognised member of $S$. Now note that this is the twofold outcome of one and the same process that emphasises different causal relationships, i.e., being genealogically related and sharing genetic and phenotypic properties. Yet, ultimately, both relationships involve material 
inheritance: common descent is both the causal process linking part $a$ and part $b$ of $S$ and the causal process making member $a$ genetically and phenotypically similar to member $b$. To put it in other words: if species are biological entities, then an organism $a$ is a part of individual/whole $S$ because it stands in a particular biological relationship with $S$ which happens to be mereological. Equally, if organism $a$ is a member of class $S$, it is because it stands in a particular biological relationship with $S$ which happens to be set-theoretical. Thus, mereological and set-theoretical relations should be, in the case of things like biological species, interpreted biologically because they are biologically realised.

The putative incompatibility between the individuality and HPC kind theses highlighted in Sect. 3.1 stems from the fact that, prima facie, they seem to identify species' part-hood and membership conditions differently. In the case of the individuality thesis, in order to characterise part-hood conditions explicit reference to the causal relations between parts is needed. Conversely, in the case of the HPC kind thesis, the characterisation of membership conditions makes reference to the genetic and phenotypic properties of the relevant cluster (see footnote 8). But this difference is spurious. In fact, causally speaking the two theses both make reference to specific causal relations and interactions between organisms in terms of their participation in causal processes. Causally speaking, the individuality thesis claims that an individual is a whole made of parts; parts are causally related to other parts because they participate in specific causal processes, where these causal processes make the whole individual-like; for instance, $a$ is part of the whole/species-as-individual $S$ if it is causally related (e.g., by reproduction or descent) to another part $b$ of $S$. The specific causal relationship between $a$ and $b$ contributes to make $S$ a cohesive whole. In the HPC case, a kind has members and its members are identified by property clusters; members are causally related to other members because they participate in homeostatic processes, where these causal processes make the participating members genetically and phenotypically similar and the relative species kind-like; for instance, $a$ is member of the species-as-HPC-kind $S$ if it shares a subset of the properties of the cluster $C$ that characterises species $S$ with $b$.

When a causal approach is endorsed, we can see that the two main putative differences between the two views are apparent. The first is a difference in emphasis: while the individuality thesis stresses the causal participation of the organisms of the same species in specific causal processes, the HPC kind thesis might be interpreted as stressing the similarity between those organisms; however, their similarity is determined by their participation in causal processes, i.e., similarity is the causal effect of such participation. To strengthen this point, consider again the metapopulational structure of a species. If you look at the sequence of Mendelian populations through time, it is clear that what keeps together the successive generations of populations are causal relations such as reproduction and descent. But if you look at the metapopulation at time $t$ (i.e., if you consider just one generation), what catches the eye is the similarity among the organisms that compose the species (since gene flow and descent are inter-generational processes). The second apparent difference stems from the fact that certain causal processes might render a species individual-like while others might make it kind-like. But even in this case the difference is spurious. What needs to be understood is the nature of the causal relations and interactions 
between the organisms of a lineage in terms of their participation in causal processes. It is highly probable that the homeostatic processes keeping the members of species genetically and phenotypically homogeneous are different (e.g., developmental and genetic homeostasis in the case of one species and genetic drift, directional selection and adaptive introgression in the case of another); accordingly, different species may be individual-like and kind-like in virtue of different processes. This species-specificity and uniqueness was already highlighted by Mayr (1963) when referring to "species-specific homeostatic mechanisms". Our point is that it is not possible that a single species with a specific origin, life history, metapopulation structure and gene-phene pool is individual-like because of the causal contribution of a set of biological processes $x$ and kind-like because of the causal contribution of a different set of biological processes $y$. We here argue that if these causal processes render the species individual-like, then they also render it HPC-kind-like and vice versa. On the one hand, the various parts of a species are kept together tightly by means of their causal relations and through their participation in specific biological processes that make the whole cohesive, integrated and individual-like. On the other hand, the cluster of co-occurring genetic and phenotypic properties partially shared by the members of the species-as-kind is kept together as a homeostatic cluster through the action of the very same specific biological processes.

Ultimately, we argue that, because the same processes cause a species to be both individual-like and kind-like, that entity is both an individual and a kind. The contrast between SAI and HPC can then be read as occurring at an epistemological rather than at an ontological level. As a matter of fact, SAI and HPC look at the same biological reality from two alternative perspectives, i.e., they are describing two sides of the same coin: the cohesiveness of biological species as wholes and the compactness of their gene-phene pools. For instance, processes like developmental and genetic homeostasis, made possible by reproduction, equally make a species individual-like and kind-like at the same time. Some advocates of the individuality thesis (e.g. Hull 1978; Gould 2002: chapter 8) argued that these homeostatic processes render the species cohesive like an individual (and unlike a kind). But also note that the effect of these processes is homeostatic in the sense that they maintain the species' gene-phene pool stable; that is, the processes rendering the species a cohesive individual are also those maintaining the stability of its distinctive and characterising HPC. The reason is obvious: developmental homeostasis canalises the development of the organisms of the species by making them phenotypically uniform, while genetic homeostasis (i.e., stabilising selection eliminating less fit hybrids and "deviant" organisms) has an equivalent genetic effect.

The inter-translatability argument states that individual-talk and kind-talk are inter-translatable. The argument from causality we have here proposed shows that the two metaphysical views are consistent on the basis of making reference to the same biological processes. Thus, as far as sexual species are concerned, the argument from causality supports the inter-translatability argument that each species can be treated as both an individual and as an HPC kind on the basis of the metaphysical thesis that each species is, at the same time, an individual and an HPC kind. We therefore argue that there is a fact of the matter concerning the question of the metaphysical status of sexual species: it is not a matter of convention to treat sexual 
species as individuals or as kinds, but it is rather a matter of looking at the causal processes determining species' identity.

\subsection{Individuality and kindness are a matter of degree}

In this section we characterize our position in more detail and evaluate the implied corollary that both individuality and kindness may come in degrees. In Sect. 2 we observed that there might be a difference not only in the kind of homeostatic processes at play, but also in the homeostatic strength of the processes. As a consequence of this, a species might be more individual-like (i.e., a more or less cohesive whole) and more kind-like (i.e., a more "natural" cluster sensu Boyd) at time $t$ and less at (past or future) time $t_{n}$ and vice versa. The reason (also highlighted by Slater 2015: p. 393) is the following. Evolutionary processes such as, for instance, selection and drift can be homogenizing forces in specific circumstances, but not generally. It is again a contingent matter depending on the peculiar history and present status of the metapopulation whether evolutionary processes will have a homogenizing rather than a disruptive effect. It is useful to think of this dynamic as a clash between the homeostatic processes that maintain species integrity (i.e., its genetic and phenotypic uniformity) and the processes creating (heterogenic) and maintaining (heterostatic) genetic and phenotypic variation. Thus, we suggest that individuality and kindness come in degrees, depending on the strength of homeostasis and on the prevalence of homeostasis vis à vis heterostasis.

In order to show this, let us consider an example concerning our species. Mayr argued that species' homeostasis is often characterized by inertia:

... owing to the hundreds or thousands of generations that have undergone preceding selection, a natural population will be close to the optimal genotype... All the mutations of which this genotype is capable and that could lead to an improvement of this standard phenotype have already been incorporated in previous generations. (Mayr 2001: 50)

However, homeostatic inertia can be eclipsed. For instance, consider the evolution of lactose tolerance. In this case, mutation acts as a heterogenic process: several mutations associated with the expression of the lactase gene allowing humans to process lactose occurred in different geographic areas in the last 10.000 years or so (Tishkoff et al. 2007). Given the existence of heterogenesis, with what frequency does heterostasis happen? The chief reason for thinking that heterogenesis does not usually translate into stable polymorphisms is that selection is assumed to mostly fix one variant, i.e., to be stabilising (West-Eberhard 2003: p. 6 ff.). But the frequency of stabilising selection compared to other forms of selection depends on the constancy of the developmental and evolutionary environments in which the species lives. As a matter of fact, in the case of lactose tolerance, directional selection has been acting as a heterostatic process: the lactose tolerance mutations have spread, partially disrupting the homeostatic inertia of our species, with a significant subpopulation of contemporary humans lactose tolerant. The present human dimorphism exhibits the underlying genetic variation at the metapopulation level and the evolution of lactose 
tolerance that is currently taking place. Obviously, we are not here arguing that this is an impending case of sympatric speciation with the lactose-tolerant and intolerant human populations slowly diversifying and separating as distinct lineages. What we claim is rather that the maintenance of the present dimorphism or the eventual fixation of the lactose tolerant phenotype (in one of its known genetic variants or others) will depend on the present and future status of the human metapopulation and the relative strength of different evolutionary forces. In a scenario in which, in different ecological and social settings, the lactose tolerant and lactose intolerant traits maintain fitness-enhancing properties (respectively an environment where domesticated cattle are abundant, milk extraction techniques are sufficiently refined etc. vs. an environment with increasing availability of milk substitutes, not enough cattle to meet population needs etc.) disruptive selection might act as a heterostatic force. Conversely, given a change in this setting (e.g., the increasing fitness of the lactose tolerant phenotype due, for instance, to the rising importance of milk and dairy consumption on a planet devastated by underproduction of alternative food resources, or enhanced immunity to zoonotic diseases transmitted by cattle), directional selection might act as a homeostatic force.

Besides this speculation, the example shows that homeostasis is counterbalanced by a number of context-relative and species-specific heterogenic and heterostatic forces and that the prevalence of these forces determines the conditions for speciation. In particular, the example shows that the existence of polymorphisms is an important-though per se insufficient-condition for sympatric speciation. It is insufficient because a heterostatic force must be at play to disrupt homeostasis and actually diversify the lineage. When polymorphisms are available, for instance, disruptive selection can act as a heterostatic force. Indeed, as Mallet (1995: p. 299) argued, "To understand speciation, we need to understand when disruptive selection can outweigh gene flow between populations." Ultimately, it is a contingent matter depending on the peculiar history and present status of a species whether specific developmental and evolutionary processes will have a homogenizing rather than a disruptive effect.

The example above is also meant to show that heterostasis renders simultaneously the species less individual-like (by making it less cohesive) and less HPC kind-like (by making its distinctive homeostatic cluster less homogeneous). Starting with the $\mathbf{A Q 2}$ issue of individuality, the notion of species cohesion might be interpreted, following Barker and Wilson (2010, pp. 64-65), in at least two ways: as response cohesion, when its component organisms respond as a unit to some kind of intervention (causal interaction among them is not required, they may respond similarly but independently), or as integrative cohesion (i.e., when the causal interactions between most or all of the organisms make it function as a whole). Barker and Wilson argue that, typically, biological species only display the first kind of cohesion-i.e., by responding as a unit to evolutionary pressures - but lack integrative cohesion. Thus, according to them, species cannot be considered individuals because, being "gappy" entities (for instance in the sense that their members are physically separated), most or all species members are unable to causally interact appropriately in order to achieve integrative cohesion (for instance, because certain behaviours may preclude gene flow). At the same time, they admit that "response cohesion comes in degrees". 
We suggest the same applies to integrative cohesion, with the consequence that also individuality comes in degrees, resulting in species whose individuality is more or less "organismal" (recall the distinction between the two formulations of SAI sketched in Sect. 3.1).

Consider also that gene flow might not be the only means to achieve integrative cohesion. At least Eldredge and Gould (1972), Templeton (1989) and Mallet (1995) have maintained that species can evolve as cohesive units even in the absence of significant gene flow. For instance:

The coherence of a species, therefore, is not maintained by interaction among its members (gene flow). It emerges, rather, as an historical consequence of the species' origin as a peripherally isolated population that acquired its powerful homeostatic system ... if ... stability is an inherent property both of individual development and the genetic structure of populations, then its power is immeasurably enhanced, for the basic property of homeostatic systems, of steady states, is that they resist change by self-regulation. (Eldredge and Gould 1972: 114$)^{11}$

The origination process of our species provides an illustration of the Eldredge's and Gould's point. An accredited hypothesis postulates an allopatric cladogenetic scenario whereby an estimated population of 10.000 organisms represented the ancestral population of $H$. sapiens (Relethford 2008). Supposing that ancestral humans were tightly interacting so as to constitute an organism-like functional system, this might represent a case of integrative cohesion whereby all original parts are sufficiently interconnected as to constitute a strongly individual-like whole. This putative lack of original gappines was then protected by developmental and genetic homeostasis. Thus, whether a species displays integrative cohesion depends on the particular species and on the particular moment of its history taken into consideration. Not every species is gappy, and their gappiness might increase (or decrease) through time.

Notice that the cohesion Eldredge and Gould hypothesise would also imply genetic and phenotypic uniformity (genetic uniformity is the outcome of genetic homeostasis and phenotypic uniformity is the outcome of developmental homeostasis). Secondly, species' cohesion might change through time, passing from being integrative to being merely responsive, or even weaker (and vice versa). This means that, passing to the issue of kindness, also genetic and phenotypic homogeneity comes in degrees, in parallel with individuality.

HPC-kindness is the result of exactly the same biological conditions we have stressed so far: the prevalence of homeostatic, homogenising and cohesive processes over heterogenic and heterostatic ones. If the former prevail, the cluster will be more tightly knit. We thus suggest that when homeostatic processes prevail over heterostatic ones, the species will be concomitantly a whole whose parts are more

11 It may be objected that the kind of cohesiveness Elredge and Gould are talking about here is responsiveness cohesion. However, their reference to a homeostatic system implies the existence of a causal interactions among the members of the population beyond gene flow. 
cohesive (hence, more organism-like) and a cluster whose characterizing properties are more tightly knit (hence, more natural sensu Boyd, as an HPC kind). Conversely, when heterostatic processes prevail, the conditions leading to potential speciation would emerge. One outcome of the prevalence of heterostatic processes could be illustrated by the evolution of our species: migrations out of Africa, interbreeding with other hominin species, colonization of various continents, etc. have concomitantly rendered our species an increasingly less cohesive whole and a less phenotypically uniform cluster. A different outcome of the prevalence of heterostatic processes might result in speciation. The prevalence of heterostatic processes might have the consequence that the cohesive individual would ultimately cease to exist as such (for instance, when it will "become" two individuals), and the cluster would be increasingly disjointed and reflect increasing multi-modality in phenotypic expression, until its ultimate disintegration (in the sense that two different clusters will be eventually needed to characterise two different species). For example, the existence of significant polymorphisms (e.g., of non-neutral variants) renders simultaneously the species-individual less organism-like (because, for instance, disruptive selection might lead to diversification of the lactose-tolerant and intolerant human populations) and its distinctive homeostatic cluster less homogeneous (because, for instance, the human metapopulation is characterized by dimorphism concerning lactose tolerance).

It might be objected that in some cases the existence of polymorphisms might make the species more organism-like, for example, through the division of labour among the parts (think of the different castes seen in ant and termite colonies). ${ }^{12}$ If this is the case, then some processes seem to generate a less tightly-knit and more disjointed HPC kind while simultaneousty generating a more cohesive individual. Even though we concede that this might happen, we would also like to stress that nonetheless the differentiated parts display both a certain, general, level of similarity and a stronger level of similarity "locally", that is, between the members of the different castes (i.e., the higher-level parts/members) of the species.

To conclude, at different moments of its history, a species might be more an individual (i.e., more organism-like) or more natural an HPC kind than at other moments. What makes sexual species individuals also concomitantly makes them HPC natural kinds. Whether the same holds for asexual species (in case they were considered species at all) remains an open question.

\section{Conclusion}

We have argued that our empirical approach vindicates the ecumenical stance that species are at the same time individuals and HPC kinds. The starting point of our argument is the general species concept, which captures what all species concepts have in common, i.e., that species are segments of metapopulation lineages. We then articulated in more detail the concept of metapopulation, ending up with what

12FL01 12 We thank a reviewer for raising this objection. 
we called a "minimal characterization" of species. Then, adopting the empirical stance that seems to be required by the minimal characterization (namely that only by considering the species-specific origination process, metapopulation dynamics and gene-phene pool it is possible to recognize a particular segment of a lineage as a species and, furthermore, as that particular species), we have moved to consider species taxa and their identity conditions over time. By looking at the biological processes that led to the origin of new species, to those impinging on their life histories, to those affecting their metapopulation dynamics and creating their metapopulation structures and, finally, to the homeostatic and heterostatic processes affecting their history, we believe the metaphysical issue concerning the nature of species could also be settled. One possible outcome of our analysis could be that, given the uniqueness of the biological processes punctuating every species' life history, some form of ontological pluralism should be endorsed: perhaps some sexual species are individuals and others HPC kinds. However, we excluded that outcome on the basis of our causal argument: because the biological processes at the basis of the individuality and kindness of a species are the same, what shall be concluded is that species taxa are at the same time both individuals and HPC kinds. Being an individual, it is identifiable in terms of mereological relationships. Being a kind, it is characterizable in terms of an HPC cluster, however formed and maintained.

Acknowledgements We thank Ingo Brigandt, Kevin de Queiroz, Matthew Slater, and Achille Varzi for incisive feedback and suggestions. We also thank the anonymous reviewers for their stimulating feedback, and the audience at the EPILOG seminar (in particular Cristina Amoretti and Marcello Frixione) of the University of Genoa, Italy, where the ideas proposed in this article starting to take shape. We acknowledge the financial support of the Fundação para a Ciência e a Tecnologia (BIODECON R\&D Project Grant PTDC/IVC-HFC/1817/2014). Davide Vecchi also acknowledges the financial support of the Fundação para a Ciência e a Tecnologia (Grant No. SFRH/BPD/99879/2014; Grant No. UID/FIL/00678/2019) and of the Fondo Nacional de Desarrollo Científico y Tecnológico de Chile (Grant No. 1171017).

\section{References}

Assis, L. C. S., \& Brigandt, I. (2009). Homology: Homeostatic property cluster kinds in systematics and evolution. Evolutionary Biology, 36, 248-255.

Barker, M. J. (2010). Specious intrinsicalism. Philosophy of Science, 77, 73-91.

Barker, M. J., \& Wilson, R. A. (2010). Cohesion, gene flow, and the nature of species. The Journal of Philosophy, 107(2), 61-79.

Boyd, R. (1999). Homeostasis, species, and higher taxa. In R. A. Wilson (Ed.), Species. New interdisciplinary essays (pp. 141-186). Cambridge, MA: MIT Press.

Brigandt, I. (2009). Natural kinds in evolution and systematics: Metaphysical and epistemological considerations. Acta Biotheoretica, 57, 77-97. https://doi.org/10.1007/s10441-008-9056-7.

Brogaard, B. O. (2004). Species as individuals. Biology and Philosophy, 19, 223-242.

Burggren, W. (2016). Epigenetic inheritance and its role in evolutionary biology: Re-evaluation and new perspectives. Biology, 5, 24. https://doi.org/10.3390/biology5020024.

Colless, D. H. (2006). Taxa, individuals, clusters and a few other things. Biology and Philosophy, 21, 353-367.

de Queiroz, K. (1995). The definitions of species and clade names: A reply to Ghiselin. Biology and Philosophy, 10, 223-228.

de Queiroz, K. (1999). The general lineage concept of species and the defining properties of the species category. In R. A. Wilson (Ed.), Species: New interdisciplinary essays (pp. 49-89). Cambridge, MA: MIT Press. 
de Queiroz, K. (2005a). Ernst Mayr and the modern concept of species. PNAS, 3(102), 6600-6607. de Queiroz, K. (2005b). Different species problems and their resolution. BioEssays, 27, 1263-1269. de Queiroz, K. (2007). Species concepts and species delimitation. Systematic, 56(6), 879-886.

Devitt, M. (2008). Resurrecting biological essentialism. Philosophy of Science, 75, 344-382.

Dobzhansky, T. (1950). Mendelian populations and their evolution. The American Naturalist, 84(819), 401-418.

Doolittle, W. F., \& Zhaxybayeva, O. (2009). On the origin of prokaryotic species. Genome Research, 19, $744-756$.

Dupré, J. (1995). The disorder of things: Metaphysical foundations of the disunity of science. Cambridge, MA: Harvard University Press.

Eldredge, N., \& Gould, S. J. (1972). Punctuated equilibria: An alternative to phyletic gradualism. In T. J. M. Schopf (Ed.), Models in paleobiology (pp. 82-115). San Francisco: Freeman Cooper.

Ereshefsky, M. (2010). Microbiology and the species problem. Biology and Philosophy, 25, 553-568. https://doi.org/10.1007/s10539-010-9211-9.

Ereshefsky, M. (2014). Species, historicity and path dependency. Philosophy of Science, 81(5), 714-726.

Ereshefsky, M., \& Matthen, M. (2005). Taxonomy, polymorphism, and history: An introduction to population structure theory. Philosophy of Science, 72(1), 1-21.

Gayon, J. (1996). The individuality of the species: A Darwinian theory? From Buffon to Ghiselin, and back to Darwin. Biology and Philosophy, 11, 193-204.

Ghiselin, M. T. (1974). A radical solution to the species problem. Systematic Zoology, 23, 436-444.

Ghiselin, M. T. (1995). Ostensive definitions of the names of species and clades. Biology and Philosophy, $\mathbf{A Q 3}$ 10, 219-222.

Gould, S. J. (2002). The structure of evolutionary theory. Cambridge, MA: Belknap Press of Harvard University Press.

Hull, D. (1976). Are species really individuals? Systematic Zoology, 25(2), 174-191.

Hull, D. (1978). A matter of individuality. Philosophy of Science, 45(3), 335-360.

Hull, D. L. (1992). Individual. In E. Fox Keller \& E. A. Lloyd (Eds.), Keywords in evolutionary biology (pp. 181-187). Cambridge, MA: Harvard University Press.

Kitcher, P. (1984). Species. Philosophy of Science, 51, 308-333.

LaPorte, J. (2004). Natural kinds and conceptual change. Cambridge: Cambridge University Press.

Levins, R. (1970). Extinction. Lectures on Mathematics in the Life Sciences, 2, 75-77.

Mallet, J. (1995). A species definition for the modern synthesis. Trends in Ecology \& Evolution, 10, 294-299.

Mayr, E. (1963). Animal species and evolution. London: Belknap Press of Harvard University Press.

Mayr, E. (1970). Populations, species, and evolution. Cambridge: Harvard University Press.

Mayr, E. (1988). The why and how of species. Biology and Philosophy, 3, 431-441.

Mayr, E. (2001). What evolution is. New York: Basic Books.

Okasha, S. (2002). Darwinian metaphysics. Species and the question of essentialism. Synthese, 131, 191-213.

Queller, D. C., \& Strassman, J. W. (2009). Beyond society: The evolution of organismality. Philosophical Transactions of the Royal Society of London B: Biological Sciences, 2009(364), 3143-3155.

Relethford, J. H. (2008). Genetic evidence and the modern human origins debate. Heredity, 100, 555-563. Reydon, T. (2009). Species and kinds: A critique of Rieppel's "one of a kind" account of species. Cladistics, 25, 660-667.

Richards, R. (2010). The species problem. Cambridge: Cambridge University Press.

Ridley, M. (2004). Evolution. Oxford: Blackwell.

Rieppel, O. (2007). Species: Kinds of individuals or individuals of a kind. Cladistics, 23, 373-384.

Rieppel, O. (2009). Species as a process. Acta Biotheoretica, 57, 33-49.

Samadi, S., \& Barberousse, A. (2006). The tree, the network, and the species. Biological Journal of the Linnean Society, 89, 509-521.

Slater, M. H. (2013). Are species real? An essay on the metaphysics of species. London: Palgrave Macmillan.

Slater, M. H. (2015). Natural kindness. British Journal for the Philosophy of Science, 66(2), 375-411.

Stamos, D. (2003). The species problem. Lanham, MD: Lexington Books.

Templeton, A. R. (1989). The meaning of species and speciation: A genetic perspective. In D. Otte \& J. A. Endler (Eds.), Speciation and its consequences (pp. 3-27). Sunderland: Sinauer Associates Inc.

Tishkoff, S. A., et al. (2007). Convergent adaptation of human lactase persistence in Africa and Europe. Nature Genetics, 39, 31-40. 
Synthese

Varzi, A. (2016). Mereology. The Stanford Encyclopedia of Philosophy (Spring 2016 Edition), Edward N.AQ4 Zalta (ed.). http://plato.stanford.edu/archives/spr2016/entries/mereology/.

West-Eberhard, M. J. (2003). Developmental plasticity and evolution. New York: Oxford University Press.

Wilkins, J. S. (2009). Defining species. A sourcebook from antiquity to today. New York: Peter Lang.

Wilson, E. O. (1975). Sociobiology: The new synthesis. Cambridge, MA: Harvard University Press.

Wilson, R. A. (1996). Promiscuous realism. British Journal for the Philosophy of Science, 47, 303-316.

Wilson, R. A., Barker, M. J., \& Brigandt, I. (2007). When traditional essentialism fails: Biological natural kinds. Philosophical Topics, 35, 189-215.

Wright, S. (1931). Evolution in Mendelian populations. Genetics, 16, 97-159.

Publisher's Note Springer Nature remains neutral with regard to jurisdictional claims in published maps and institutional affiliations. 
Journal: $\mathbf{1 1 2 2 9}$

Article: $\quad 2199$

\section{Author Query Form}

\section{Please ensure you fill out your response to the queries raised below and return this form along with your corrections}

\section{Dear Author}

During the process of typesetting your article, the following queries have arisen. Please check your typeset proof carefully against the queries listed below and mark the necessary changes either directly on the proof/online grid or in the 'Author's response' area provided below

\begin{tabular}{|l|l|l|}
\hline Query & Details Required & $\begin{array}{l}\text { A u t h o r's } \\
\text { Response }\end{array}$ \\
\hline AQ1 & $\begin{array}{l}\text { Reference LaPorte (2007) is cited in the text, but not } \\
\text { provided in the list. Please provide the reference in the } \\
\text { list or delete this citation. }\end{array}$ & $\begin{array}{l}\text { Barker and Wilson (2014 has been changed to Barker } \\
\text { and Wilson (2010) so that this citation matches the list. }\end{array}$ \\
\hline AQ2 & $\begin{array}{l}\text { Reference Ghiselin (1995) is given in the list, but not } \\
\text { cited in the text. Please cite in the text or delete from } \\
\text { the list. }\end{array}$ & \\
\hline AQ3 & $\begin{array}{l}\text { Please provide accessed date for the reference Varzi } \\
\text { (2016), if possible. }\end{array}$ & \\
\hline AQ4 &
\end{tabular}

